\title{
IMPACT OF CONSUMER INNOVATIVENESS ON REALLY NEW PRODUCT ADOPTION
}

\begin{abstract}
Purpose - This study explores consumer innovativeness as a personality trait and addresses the hedonic, social, cognitive, and functional motivational elements that lie behind consumer innovativeness. It explores the weak relationship between consumer innovativeness and really new product (novel innovation) adoption and challenges the classic relationship between consumer learning, attitude and intention.

Design/methodology/approach - This study adopts a quantitative approach, gathering survey data via an institutional online platform. 300 participants were recruited. Participants were directed to a website presenting the information of the product with the inclusion of 2D and 3D images and an avatar. For data analysis, CFA and Structural Equation Modelling (SEM) were used.

Findings - Results indicate a positive impact of attitude on comprehension and intention. In addition, hedonic innovativeness positively impacts customer's attitude, whereas there is a negative relationship between social innovativeness and attitude. Motivational elements of innovation, with the exception of hedonic motivation, positively influence purchase intention.

Research limitations/implications - The main limitation of the study lies in the measurement of purchase intention, as actual purchases cannot be assessed as the products are not yet available. The findings encourage marketers to target innovators first, ideally innovators motivated by hedonic needs.

Originality/value - This study challenges the classic theories identifying the link between comprehension, attitude and purchase intention within the field of innovation. The findings indicate that while interacting with Really New Products, comprehension does not necessarily lead to attitude and intention, but attitude does positively influence both intention and comprehension

Keywords: Innovation Adoption, Really New Products, Consumer Innovativeness, Consumer Motivation

Paper type - Research paper
\end{abstract}

\section{Introduction}

Innovation is considered as a crucial competitive ability for firms (Andries et al., 2009; Nishitani and Itoh, 2016) and is an important factor in global economic growth (Golder and Tellis, 1997; Thoenig and Verdier, 2003; Balzat and Hanusch, 2004; Sohag et al., 2015). New and innovative products and services can contribute to a company's growth, competitive advantage and profitability (Steenkamp et al., 1999; Guoxin et al., 2014; Visnjic et al. 2016) and improve consumer satisfaction (Wilke and Sorvillo, 2005; Pan and Nguyen, 2015). In this study, only novel innovative products, also called Really New Products (RNPs) are taken into consideration (Gregan-Paxton et al., 2002; Hoeffler, 2003; Feiereisen et al., 2008; Zhao et al., 2012). RNP introduction is rising as technology is advancing. Through RNPs an organization can gain a competitive advantage and enter new markets (Zang and $\mathrm{Li}, 2017$ ). In today's globally competitive rapidly changing markets, firms need to introduce innovations in the form of RNPs rather than incrementally new products (INPs) to survive (Chao et al., 2012; Song et al. 2005) . RNPs are identified as products that are very different to existing products, and offer greater benefits than INPs; however consumers need to change their behavior in order to achieve the potential benefits of RNPs and there are uncertainties concerning the cost-benefit trade-offs for consumers in the utility and consumption of RNPs (Hoeffler, 2003; Alexander 2008). Although RNPs are being introduced into the marketplace, $40 \%$ to $90 \%$ of new products fail, with highly innovative products failing at a greater rate (Cierpicki, 2000; Ronald et al., 2006; Heidenreich and Kraemer, 2016). In order to help understand RNPs' high failure rates, new product adoption and diffusion of innovation factors, as well as factors affecting market and consumers' acceptance of innovation need to be examined (Hauser et al., 2006; Brem and Viardot, 2016; Demirel and Peyne, 2018). By improving consumers' innovation adoption rate, RNPs will have a better chance of being successful within the marketplace. 
Early research established a link between the adoption of new products and individuals' innovativeness (Midgley and Dowling, 1978; Hirschman, 1980). Dedehayir et al.'s (2017) review of innovation diffusion studies, confirmed that a high level of innovativeness as a personality trait leads to innovation adoption. Consumer innovativeness, conceptualized as Innate Innovativeness and Actualized Innovativeness (Midgley, 1977), significantly impacted upon consumers' adoption of new products (Im et al., 2003; Rogers, 2003; Weijters and Roehrich, 2004; Im et al., 2007) . Rogers' Diffusion of Innovation theory differentiates between consumers' innate innovativeness, with those with the highest innovativeness being classed as innovators (Rogers, 2003). Innovators play a critical role in the diffusion process by importing the innovation from outside the social system's boundaries (Rogers, 2003). Innovators are active information seekers when interacting with new ideas, and they see online information seeking and adoption as fun, safe, quick and easy (Goldsmith and Laffertty, 2002; Rogers, 2003).

Studies around innate innovativeness have indicated a positive but weak relationship between consumer innovativeness and new product adoption (Goldsmith et al., 1995; Citrin et al., 2000; Im et al., 2007; Guoxin et al., 2014); the reasoning behind this weak relationship is not well understood. For example, Guoxin et al. (2014) looked into new product characteristics and consumer innovativeness; Chao et al. (2012) examined domain specific innovativeness but recommended future research to explore the reason behind the weak relationship. Why a weak relationship exists is, as such of interest for marketing researchers and practitioners as understanding innovator characteristics that influence RNP adoption (Ronald et al. 2006) may help to reduce the high failure rate of RNPs. Although there is a body of literature examining consumers' characteristics related to their innovativeness, the impact of motivational innovativeness elements on consumer comprehension, attitude and purchase intention towards RNPs has received little attention.

This research aims to provide insight into the influence of motivational consumer innovativeness elements (i.e., cognitive, functional, hedonic, and social innovativeness) on consumer RNP comprehension, attitude and purchase intention. The study develops and tests a conceptual model based on existing innovation frameworks that examines the links between innate innovativeness, and a consumer's comprehension of, attitude towards, and purchase intention towards, RNPs (Hirschman, 1980; Goldsmith and Hofacker, 1991; Hirunyawipada and Paswan, 2006; Hoffmann and Soyez, 2010; Bartels and Reinders, 2011). The paper examines literature from diffusion of innovation, consumer innovativeness, consumer behavior and consumer motivation, and innate innovativeness perspectives. The methodology is then explained followed by findings and discussion which includes limitation and areas for future research.

\section{Literature Review and Theoretical Background}

\subsection{Diffusion Theory}

Diffusion is described as a process "by which an innovation is communicated through certain channels over time among the members of a social system" (Rogers, 2003, p.11), where the message is about a new idea. Rogers' theory of diffusion of innovation has been applied in various domains such as eco-innovation (Karakaya et al., 2014), IT innovation (Wu and Chiu, 2015), technological and cultural innovation (Ekdale et al., 2015) and fields such as tourism (Dibra, 2015). The main elements of this diffusion theory are innovation, communication, time and the social system. An innovation is an idea, object or practice that is perceived as new (e.g., a RNP) by individuals. The newness of the innovative product generates a degree of uncertainty in the mind of the adopter, but it also provides them with an opportunity to resolve a problem that they are currently unable to solve using existing products. RNPs are innovations that are perceived as high-risk, requiring more cognitive effort and learning by individuals to comprehend (e.g. Gregan-Paxton et al., 2002; Feiereisen et al., 2008). Hence, literature has looked into facilitating consumer comprehension by introducing learning strategies (i.e. Feiereisen et al., 2008), reducing individuals' perceived risk (i.e. Aboulnasr and Tran, 2019) or improving communication for better adoption of RNPs (i.e. Ajmal, 2019). This paper considers the adoption of RNPs and consumer innovativeness. Potential adopters will search for information in order to reduce their uncertainty and conclusively adopt the innovation (Rogers, 2003). Communication facilitates the process by which participants share information with one another to reach a mutual understanding of the RNP. Potential adopters seek 
information via various communication channels, indicating that diffusion is a very social process (Rogers, 2003).

The adoption process is not the same for all people (Rogers, 2003; Janson, 2010). One aspect of difference is time. Time is defined by three elements: first, the innovation-decision process; second the rate an innovation is adopted by an individual; and, third, the rate an innovation is adopted within a system. The rate of innovation adoption by the individual, the focus of this study, determines which consumer adopter category a consumer lies within (e.g. innovator, early adopter etc.). This individual element of time within diffusion theory explains how individuals differ in their rate of innovation adoption. Within consumer behaviour research, innovativeness is described variously as a "willingness to change" (Hurt et al.,1977; Im et al., 2003), a "predisposition to buy new products" (Hirschman, 1980; Midgley and Dowling, 1993) and a "preference for new and different experiences" (Pearson, 1970; Hirschman, 1980; Raju, 1980) cited in Tellis et al., (2009) p.2). Consumer innovativeness is, as such, a tendency to purchase different and new products, rather than remain with former choices and consumption patterns (Venkatesh and Nicosia, 1997). The shorter the adoption time, the greater the indication is that the consumer is willing to change their behaviour and adopt the new concept or product.

Consumer characteristics influence innovation diffusion. These consumer characteristics include gender (Tellis et al,. 2009), creativity (Hirschman, 1980; Roger, 2003), motivational factors (Vandecasteele and Geunes, 2010), decision-making styles (Rogers, 2003), technological capabilities (Kim, 2016), interest, enthusiasm, excitement and willingness to adopt (Salari and Shiu, 2015), and learning (Bandura, 1977; Franks and Oliver, 2012). Rogers (2003) showed that the innovation decision-making process is an information seeking and processing activity, motivating individuals to decrease uncertainty about the advantages/disadvantages of the innovation (Rogers, 2003). Vandecasteele and Geunes (2010) explained how individuals are motivated by various forms of sensory information or needs, to adopt an innovation. Motivation is studied in different fields to understand consumers' behaviour. For example, motivation is used as a segmentation strategy in tourism industry (Guttentag et al., 2017) and as a factor explaining consumer pro-environmental behaviour (Rezvani et al., 2018). Motivation is also explored as inner mental reasons within decision psychology, an understudied area in the innovation diffusion literature (Zenobia and Weber, 2011). This paper aims to explore consumer motivation as an individual trait, and its relationship to consumer innovation adoption.

Another element impacting on the diffusion of innovation is the product's attributes. Studies have revealed how product attributes, such as perceived advantageousness (Roger, 2003) and perceived usefulness (Irani, 2000), influence the time of adoption. A RNP's unique characteristics can therefore contribute to the time of adoption. RNPs are perceived as high-risk products; hence perceiving RNPs as advantageous and useful requires more cognitive effort by individuals, and more learning is required to comprehend RNPs (e.g. Gregan-Paxton $e t$ al., 2002; Feiereisen et al., 2008). The communication channel also impacts upon innovation adoption. Consequently, selecting the right communication channel is essential in the diffusion process (Midgley and Dowling, 1978). The Internet is commonly used as a promotional channel for RNPs in order to create product awareness and increase new product adoption rate (e.g. Bickart and Schindler, 2001; Prince and Simon, 2009; Lyytinen et al., 2015).

Overall, individuals with higher levels of innovativeness are active information seekers with regards to new ideas. They can cope with a higher level of uncertainty in comparison to other adopter types (Rogers, 2003). They have the quickest time-of-adoption and are more likely to try new products. They believe they are more knowledgeable about online shopping and they purchase more products online. Additionally, they are more likely to view online shopping as quicker, cheaper, safer and more fun than traditional shopping methods (Goldsmith and Lafferty, 2002). Therefore, initial promotion of innovations (such as RNPs) through targeting individuals with a higher level of innovativeness, gives them a better chance of adoption into a new social system. 


\subsection{Consumer Innovativeness}

Innovativeness is "the degree to which an individual or other unit is relatively earlier in adopting new ideas than other members of a system" (Rogers, 1995, p.37). Innovativeness can be measured as a behaviour, as a global personality trait, and/or as a domain-specific personality trait (Goldsmith and Foxall, 2003; Salari and Shiu 2015). Consumer innovativeness has been conceptualized in two main streams: "Innate Innovativeness" and “Actualized Innovativeness" (Midgley, 1977, cited in Roehrich, (2004) p.672).

The concept of innovativeness emerged in the academic literature in the 1970s (Salari and Shiu, 2015). Midgley (1977, p.75) defines innate innovativeness as "the degree to which an individual makes innovation decisions independently from the communicated experience of others". Innate Innovativeness, or "global innovativeness" (Goldsmith and Foxall, 2003), is a cognitive trait based on one's inherently innovative personality, tendency and cognitive style (Hirschman, 1980; Midgley and Dowling, 1993; Steenkamp et al., 1999). Innate Innovativeness refers to innovative consumers as being independent decision-makers (Midgley and Dowling, 1978) and inherent novelty seekers (Manning et al., 1995). Innately innovative consumers have a tendency to buy new and different products, rather than staying with current consumption patterns and existing products (Steenkamp et al., 1999), and they have a tendency to change (Hurt et al., 1977). Innate Innovativeness is further grouped into two types of tendency to be innovative: Life Innovativeness and Adoptive Innovativeness (Roehrich, 2004). While Life Innovativeness as "the ability to introduce newness in one's life" (Vandecasteele, (2010) p.7) goes beyond merely adopting an innovation, Adoptive Innovativeness is about one's predisposition to adopt innovation, such as a consumer's interest and behavioural tendency towards innovation. This study considers Adoptive Innovativeness to further explore attitudes and behaviours towards RNPs. Consumer motivation is a driving factor in innovation adoption. Consumers are motivated by different forms of sensory information to adopt innovation (Vandecasteele and Geunes, 2010). These motivational sources are divided into four groups: the need for sensory stimulation (hedonic); the drive to search for solutions for consumption-related problems (functional); the need to have a good social status and support (social); and, the need to be involved in mentally demanding activities (cognitive). These motivational sources are examined further to understand consumers' adoptive behaviour towards RNPs.

The second stream, Actualized Innovativeness, takes a behavioural perspective. Most aspects of Actualized Innovativeness cannot be examined with RNPs, as RNPs are not available in the marketplace and consumers who are innovative in one category may not be innovative in another category (Goldsmith and Hofacker, 1991; Lyu et al., 2018). Within actualized innovation, there is vicarious innovation which explains the process by which consumers acquire information and learn about innovation (Hirschman, 1980; Midgley and Dowling, 1978). This is in line with Vandecasteele and Guenes' (2010) cognitive motivation. Due to RNPs' unique nature, understanding these products requires more cognitive effort, so more learning is required to comprehend RNPs (e.g. Gregan-Paxton et al., 2002; Feiereisen et al., 2008). Therefore if innovative consumers engage in vicarious innovativeness, due to their personality trait, they will be motivated to perform specific adoption behaviour. Figure 1 is a visual representation of innovativeness categorization, the pink boxes indicate the innovativeness category relevant to RNPs and considered in this study.

Figure 1 to be inserted

\subsection{Consumer Behaviour and innovation}

Persuasion Theory posits that learning will result in a higher purchase intention and more positive attitudes (Ratneshwar and Chaiken, 1991). Theory of Planned Behaviour (TPB) explains how attitude leads into purchase intention (Ajzan, 1991). TPB is an extension of Theory of Reasoned Action (TRA), which explains the relationship between attitude and behaviour (Ajzen and Fishbein, 1980; Fishbein and Ajzen, 1975). TRA is derived from social psychology, persuasion models and attitude theories. Ajzen (1991) extended TRA and included perceived behavioural control. Perceived behavioural control can impact both attitude and purchase intention when the behaviour is non-volitional. However, Ajzen (1991, p.188) argues that "The relative importance of attitude, subjective norm, and perceived behavioural control in the prediction of intention is expected to vary across behaviours and situations". According to Ajzen (1991), for example, if attitude is strong, 
perceived behavioural control will become less predictive. Based on these theories, comprehension is a prerequisite to the formation of attitudes, intention and behaviour, especially under the central or systematic processing route (Ratneshwar and Chaiken, 1991). Acquiring knowledge is also one of the first steps in classical (i.e. rational) decision making models (i.e. Scott and Bruce 1995). Although individuals need to pay attention to the message in order to understand RNPs, there is a high possibility of following the peripheral route in adoption of RNPs. Cacioppo et al. (1986) explains how preconceived attitude and time and effort spent on the topic, results in individuals following central or peripheral routes. Innovators are knowledgeable, risk taking individuals (Goldsmith and Lafferty, 2002). They are independent decision-makers and inherent novelty seekers, with an existing positive attitude towards innovation (Midgley and Downling, 1978; Manning et al., 1995). For example, innovators exhibited an existing positive attitude towards 3D fashion printing as an innovative product (Lyu et al., 2018), thus they might prefer a peripheral route. Therefore, there is no need for them to understand the RNPs well, in order to have a positive attitude towards RNPs. Having an existing positive attitude towards innovation, results in a better understanding of the RNPs, so it is proposed:

\section{H1a: Attitude has a positive influence on comprehension of RNPs.}

Consumers do not need to be innovators in order to learn a concept, although being an innovator might result in them putting more cognitive effort into comprehending RNPs. The relationship between comprehension, attitude and purchase intention within the innovation context is supported by the innovation decision process, a process that comprises five stages: knowledge, persuasion, decision, implementation and confirmation (Rogers, 2003). Knowledge concerns learning and persuasion happens when an individual forms a favourable or unfavourable attitude towards innovation (Rogers, 2003). Decision happens when an individual gets involved in activities leading to a choice to either adopt or reject (or their intention to adopt or reject) the innovation. These three stages can occur with RNPs, while implementation which refers to using the innovation, and confirmation which "seeks reinforcement of an innovation-decision that has already been made" (Rogers, 1995, p.20] do not apply to RNPs. This study proposes that comprehension can directly influence intention, as innovators obtain a preconceived positive attitude towards innovation. The link between attitude and intention stands, therefore:

H1b: Comprehension has a positive influence on purchase intention towards RNPs.

H1c: Attitude has a positive influence on purchase intention towards RNPs.

This study challenges the classical theories identifying the link between comprehension, attitude and purchase intention within the field of innovation. Based on this section, motivated consumer innovativeness and RNP adoption will be explored.

\subsection{Innate Innovativeness and Consumer Motivation}

Innate innovativeness can be divided up into four distinct aspects - hedonic, functional, cognitive and social (Vandecasteele and Geunes, 2010). Many consumer innovativeness researchers have considered the hedonic dimension of consumer innovativeness (e.g. Baumgartner and Steenkamp, 1996; Roehrich, 2004). Hedonic needs include needs for sensory stimulation and novelty (Hoyer and Stokbuger-Sauer, 2012). These needs replicate an individual's inherent desire for sensory pleasure (Hoyer and MacInnis, 2010). Therefore, as an innate perspective, individuals adopt innovations to satisfy their hedonic needs.

From a product perspective, hedonic innovations and functional innovations attract dissimilar types of innovative consumers (Hirschman, 1984). Considering this distinction is, as such, important when examining RNPs and how consumers perceive and adopt products. Research indicates how variables related to hedonic values work as drivers of product adoption (e.g. Davis et al., 1992; Venkatesh and Brown, 2001; Ogertschnig and Van der Heijden, 2004; Brown and Venkatesh, 2005). According to Dual Coding Theory (DCT), information, in the form of verbal and nonverbal cues, is processed, encoded, stored and retrieved in two distinct but interconnected memory system (Paivio 1986, 1991, 2007). Nonverbal systems, process and store imagery events and objects and Paivio (2007) clearly attributes emotions to this system; "affective-emotional reactions are assumed to be learned primarily in the context of nonverbal objects and events, especially including other people, and thereby become connected to nonverbal representations." (Paivio 2007, p.189). Elaboration 
Likelihood Theory (ELM) also explains two routes to persuasion, central or peripheral. When central route is followed, involved customers pay attention to the message content and there is more cognitive effort in understanding the message. If peripheral route is followed, uninvolved customers use peripheral cues to form empirical judgement (Petty and Cacioppo, 1981).

Hedonic motivation, in particular, has an influence on technology acceptance (Ahn et al., 2016). According to Jurgensen and Guesalaga (2017) if individuals enjoy the apparel shopping experience, they are more innovative in their shopping choices. Promotion factors can also influence the hedonic value perceived by individuals; for example, by adding a 3D picture within a computer mediated environment, the product's hedonic value is more observable and based on DCT learned better (e.g. Kim and Forsythe, 2007; Cano et al., 2017), and a richer interface makes the shopping experience more enjoyable improving consumers' attitude (e.g. Lee 2010). Therefore, by experiencing the product's aesthetic aspects hedonically, motivated individuals might be encouraged to learn more about the product.

Motivational theories also support hedonic motives for innovation adoption. In intrinsically motivated activities, the reward is the activity itself (Ryan and Deci, 2000). Intrinsically satisfying activities result in the satisfaction of inner psychological needs (Hull, 1943) such as hedonic needs. According to Hull (1943), by increasing the product's hedonic value, consumers will be intrinsically motivated, resulting in increased satisfaction and learning. Also, based on DCT an image has the property of concreteness, and that it is better than words in "representing the way things look or appear" which will appeal to individuals with hedonic innovativeness characteristics (Paivio 1971). Based on ELM, following peripheral cues (such as imagery) results in forming an empirical judgement. Hence the positive feeling experienced as well as the feeling of enjoyment, might facilitate consumer attitude towards the product, and consequently their purchase intention. Therefore:

H2a: Hedonic innovativeness has a positive influence on consumers' attitude towards RNPs.

H2b: Hedonic innovativeness has a positive influence on consumers' purchase intention towards RNPs.

Social needs are related to other individuals and include concepts such as status and support. In order to fulfil these needs, the presence and actions of other individuals are required (Vandecasteele and Geunes, 2010). In product innovation, consumers may want products to impress others and advance their social status (Brown and Venkatesh, 2005; Foxall, 1988). Based on DCT, affective-emotional reactions are assumed to be learned when there is a social element involved, i.e. people, hence become connected with nonverbal processing system. Non-verbal information is linked to peripheral route of persuasion which results into a product evaluation. By possessing new products, consumers can build a clear identity (Tian et al., 2001; Tian and McKenzie, 2001) and this possession is a socially acceptable way of making a unique impression (Simonson and Nowlis, 2000). The social component is, as such, an important element of consumer innovativeness (Venkatraman and Price, 1990; Rogers, 2003; Weijters and Roehrich, 2004). When a product is not yet available (RNP), consumers are less able to imagine possessing it in the near future (e.g. Ziamou, 2003). Innovative consumers are also independent decision makers (Midgley and Dowling, 1978). As a result, consumers' social motivation can negatively affect their attitude and intention. Therefore, it is hypothesised that:

H3a: Social innovativeness has a negative influence on consumers' attitude towards RNPs.

H3b: Social innovativeness has a negative influence on consumers' purchase intention towards RNPs.

Functional needs are an individual's drive to search for products that solve consumption-related problems. Functional reasons to adopt a product are mentioned in several studies such as Hirschman (1984), Venkatraman and Price (1991), Griffin (1994) and Voss et al. (2003). Some innovative consumers are attracted to functional new products (Hirschman, 1984; Venkatraman and Price, 1991) and a consumer may be motivated to buy innovative products for their utilitarian value (Babin et al., 1994; Voss et al., 2003). RNPs are products designed to solve consumer problems that cannot be solved using existing products. RNPs allow consumers to perform tasks they are unable to perform with existing products (Alexander et al., 2008). Functional needs are satisfied when an activity is undertaken in order to attain some separable outcome (Skinner, (1953) - Dichotomy of Intrinsic-Extrinsic Motivations Theory). The outcome can be a feeling of accomplishment (Vallerand, 1997), 
such as when an individual understands a new concept, resulting in a consumer's problem being solved. This is confirmed by the ELM as if one is looking to understand the utilitarian aspects of a RNP, one follows the central route to learn about the product. Therefore, highlighting the product's functionality, by using various stimuli via product promotions, can influence consumers' comprehension and intention towards RNPs. Thus:

H4a: Functional innovativeness has a positive influence on consumers' comprehension towards RNPs.

H4b: Functional innovativeness has a positive influence on consumers' purchase intention towards RNPs.

Cognitive needs and stimulation can also influence motivation and behaviour. Consumers with a cognitive need enjoy being involved in mentally demanding activities, such as reading and/or deeply processing information (Vandecasteele and Geunes, 2010). Venkatraman and Price (1990, p.294) defined cognitive innovativeness as "the desire for new experiences with the objective of stimulating the mind", while other researchers have used closely related concepts when exploring innovation behaviours (Baumgartner and Steenkamp, 1996; Vallerand, 1997). When dealing with RNPs, consumers have limited existing cognitive structures for the products (Feiereisen et al., 2008). This is due to the level of newness of RNPs, and the level of uncertainty consumers experience with RNPs. Promoting RNPs using various information presentation formats (e.g. text, imagery and 3D pictures), can help individuals to understand the RNP better, thus reducing uncertainty. Furthermore, due to the highly innovative nature of RNPs, cognitively motivated individuals may find this new experience stimulating and put more effort into comprehension of the product, which results in them following the central processing route and finding the experience more enjoyable. This results in increased comprehension. Therefore, based on the conceptual framework proposed, their effort will impact their comprehension and purchase intention. Hence:

H5a: Cognitive innovativeness has a positive influence on consumers' comprehension towards RNPs.

H5b: Cognitive innovativeness has a positive influence on consumers' purchase intention towards RNPs.

The hypotheses are summarised in the model presented in Figure 2.

Figure 2 to be inserted

\section{Methodology}

\subsection{Research Design}

This study adopted a quantitative approach, gathering survey data via an institutional online platform. Three hundred (300) participants were recruited via an online platform. Participants were then directed to a website presenting the information of the product with the inclusion of $2 \mathrm{D}$ or $3 \mathrm{D}$ pictures. All data was analysed using SPSS AMOS. A covariance-based SEM (CB-SEM) was used as the theoretical model proposed in Figure 2 is being tested (Hair et al., 2014). CB-SEM is suitable when the goal of the research is to test, confirm or compare theories, which is the aim of this study (Hair et al., 2014). CB-SEM is now the preferred method for researchers due to its ability to evaluate complex relationships (Mahadzirah et al. 2019). For data analysis, CFA and Structural Equation Modelling (SEM) were used. SEM is a popular technique used within various disciplines due to its generality and flexibility (Lei and Wu, 2007). SEM statistically "represents an extension of general linear modelling (GLM) procedure, such as ANOVA and multiple regression analysis" (Lei and Wu, 2007, p.33). SEM is mainly used due to its capability of studying relationships among latent constructs (Hair et al., 2010). The method takes a confirmatory approach to the "multivariate analysis of structural theory, one that stipulates causal relations among multiple variables" (Lei and $\mathrm{Wu}, 2007, \mathrm{p} .34$ ). The aim of SEM is to conclude if a hypothesized theoretical model is consistent with the data collected to reflect the theory (Kline, 2005; Lei and $\mathrm{Wu}, 2007)$. This technique was suitable for this study, as the relationships between multiple variables were the centre of the analysis. However, the first step in this study required the selection of an appropriate RNP. 


\subsection{Product selection}

To select an appropriate RNP, nine new products were initially identified. These products were ones with information in the form of text and pictures freely available online, at the time of selection. The products claimed to be very new and innovative and relatively easy to understand. All products were from the home and kitchen gadget category as most people are familiar with this group of products. The nine products were tested using an online questionnaire to confirm their status as RNPs in the study's population. Participants were provided with a description of each product and a picture, then they rated the products' innovativeness. For this purpose, perceived product newness was measured (Appendix 1). This scale was derived from a combination of Gregan-Paxton et al.'s (2002) definition of RNPs and Hoeffler's (2003) framework that was used in RNP related research on new product evaluation (e.g. Alexander et al., 2008). Analysing the first two questions of the scale, participants claimed not to have information about the RNPs (Questions 1 and 2 in the scale - Appendix 2). A Multivariate Analysis of Variance (MANOVA) was conducted for the remaining 4 questions of the scale to compare the means amongst the products. MANOVA is a method used to "simultaneously explore the relationship between several categorical independent variables ... and two or more dependent variables" (Hair et al., 2010, p.18). The result indicated a significant difference on perceived newness amongst $\operatorname{RNPs}(\mathrm{F}(8,26)=$ $2.95, \mathrm{p}=.01)$. From this process, the Bio-robot Fridge was selected with the highest mean (Mean $=3.52$, $\mathrm{SD}=.98$ ). This product was perceived as new, understandable and likeable and demonstrated an innovative process for refrigerating products (Appendix 2).

\subsection{Participants and sample size}

Participants for the main study (and the product testing) were recruited via Mturk, an online crowdsourcing Internet marketplace. The sample was limited to adult participants from the USA who were registered with Mturk. A sample of 300 random participants was achieved after data cleaning. The sample consisted of $42 \%$ male and 58\% female participants, with majority of sample age between 20-39, with an undergraduate degree and above. The sample size was appropriate to the analysis technique as when using SEM, to prevent data deviation from multivariate normality, an accepted ratio of 15 respondents for each parameter estimated is desired (Hair et al., 2010). The most common SEM estimation procedure is maximum likelihood estimation (MLE), which recommends a minimum sample size of 50 respondents. However, it is suggested that a model becomes more sensitive when a large sample (more than 400 respondents) are recruited; therefore a sample size of 100 to 400 is suggested. Model complexity refers to the fact that simpler models can be tested with a smaller sample. Sample size is important as it provides stability and the general preference is to have a larger sample size within the recommended range (Lei and Wu, 2007). In dealing with Average Error Variance of Indicators, research supports the use of communality as a way to approach the sample size issue. Communality refers to "the average amount of variation among the measured variables" identified by the model (Hair et al., 2010, p.636). The communality is calculated as the square of standardized construct loadings. The larger the sample size, the smaller the communalities. "Models containing constructs with communalities less than 0.5 (i.e. standardized loading estimates less than 0.7 ) require larger sample size for convergence and model stability" (Hair et al., 2010, p.636). Considering all these factors, a sample size of 300 was deemed suitable for this study.

\subsection{Measurement scales}

A questionnaire was developed using existing scales to measure innate innovativeness, comprehension, attitude and purchase intention (see Table 1). To measure innate innovativeness, Vandecasteele and Geunes' (2010) Motivated Consumer Innovativeness (MCI) was used. This 20-item scale measures the dimensions of Functional Motivated Consumer Innovativeness (fMCI), Hedonically Motivated Consumer Innovativeness (hMCI), Socially Motivated Consumer Innovativeness (sMCI) and Cognitive Motivated Consumer Innovativeness (cMCI) (Vandecasteele and Geunes, 2010). Vandecasteele and Guenes (2010) reported satisfactory Cronbach alphas for each group of items that indicated the reliability of each sub-dimension $(\alpha$ $\mathrm{sMCI}=.929 ; \alpha \mathrm{fMCI}=.907 ; \alpha \mathrm{hMCI}=.928 ; \alpha \mathrm{cMCI}=.902)$. In this study, the $\mathrm{MCI}$ scale was presented via a 7point Likert scale.

To measure comprehension a 6-item 7-point scale developed by Feiereisen et al. (2008) was used. Feiereisen developed the scale by combining a 2-item semantic differential scale by Phillips (2000) and a 4-item 7-point 
Likert scale by Moreau et al. (2001) and the scale is applied for RNP comprehension, hence suitable for this study. The KMO and Bartlett's test both support the combination of the scale items as appropriate (Feiereisen et al., 2008). All the Likert scales used 7-point scales where 1 represented "strongly disagree" and 7 "strongly agree". For attitude, a 10-item scale developed by Voss et al. (2003) was used. The scale was deemed reliable as reported by Fornell and Larcker (1981); it was measured by a 7-point semantic differential scale. Finally, to measure purchase intention, a 4-item 7-point Likert scale adopted from Moon et al. (2008) was used. A Cronbach alpha of 0.86 was reported by Moon et al. (2008) supporting the scale's reliability.

Table 1 to be inserted

\section{Findings}

4.1. Measurement development and assessment

A Confirmatory Factor Analysis was performed to assess the suitability of the scales. According to Hair et al. (2010, p.646), usually three to four fit indices provide adequate evidence of model fit. However, researchers should consider at least one incremental index (NFI, CFI etc.) and one absolute index (GFI, RMSEA, SRMR etc). Based on Hu and Bentler (1999), CFI greater than .95 and based on Bentler and Bonnet (1980) NFI greater than .90 indicates a good fit. AGFI greater than .80 and RMSEA between .05 and 0.1 are acceptable. SRMR below .5 indicates a good fit (Byrne, 1998; Diamantopoulos and Siguaw, 2000). As GFI is deemed very sensitive, it is recommended not to be used for model fit (Sharma et al, 2005). The initial model fit was not acceptable $(\chi 2=(719)=2226.890 \mathrm{p}=.000 ; \mathrm{CFI}=.867$; AGFI $=.651$; RMSEA $=.084, \mathrm{SRMR}=.0611)$, therefore the model was examined and the items with factor loadings less than 0.5 and with the biggest modification indices were removed. The error terms were not correlated as a solution to improve model fit as there was no theoretical justification to correlate error terms (i.e. Hermida, 2015). These steps resulted in the removal of 11 items (Attitude scale, items 2,3,6,8,9,10; Comprehension scale items 5,6; Purchase Intention scale item 4; Social Innovativeness item 4 and Functional Innovativeness item 1). The final model indicates a good fit for the construct measurement model $(\chi 2=(356)=680.58 \mathrm{p}=.01 ; \mathrm{CFI}=.96$; GFI=.87; AGFI= .84; NFI= .91 ; RMSEA=.055; SRMR= .043). In summery as 4 indices were deemed suitable, the model has a good fit. The factor loadings on all items are all higher than 0.70, indicating that all items loaded onto their respective constructs; this supports the convergent validity of the measurement items (Hair et al., 2010).

The internal consistency and reliability of the final scales were tested by calculating Cronbach's alpha. These ranged from .88 to .93 which was considered satisfactory. The composite reliability (CR) for each construct was calculated along with Average Variance Extracted (AVE), Maximum Shared Variance (MSV) and Average Shared Variance (ASV) (Fornell and Larcker, 1981; Hair et al., 2010). As shown in Table 2, all the conditions necessary to demonstrate reliability, convergent and discriminant validity were met. Common method bias was also tested using Harman's one factor test (Podsakoff et al., 2003) which was less than 50\% (36.2)

Table 2 to be inserted

\subsection{Hypotheses testing}

To test the hypotheses, structural equation modelling (SEM) was employed, specifically SPSS AMOS (Version 20). The goodness of fit for the SEM model is marginally different from CFA model. Model fit measurements for the structural model are $(\chi 2=(360)=686.138 \mathrm{p}=.000$; CFI= .956; GFI=.867; RMSEA=.055; SRMR=.046). The Chi-square difference test of the structural model $(\chi 2(360)=686.138)$ and the construct measurement model $(\chi 2(356)=680.58)$ was performed in order to formally check whether the difference was significant (Anderson, 1988). The critical chi-square value for $4 \mathrm{df}$ is $7.92(\mathrm{p}<0.05)$, indicating that this chisquare value is significant. Table 3 summaries the results for the hypotheses. These results show support, for most of the hypotheses (see Table 3). H1a, which indicates a strong positive influence (Cohen, 1988) of attitude towards comprehension is supported $(\beta=.562, \mathrm{p}<.001)$. A weak positive influence of comprehension towards purchase intention $(\beta=.202, \mathrm{p}<.05)$ supports $\mathrm{H} 1 \mathrm{~b}$. A moderate positive impact of attitude towards purchase intention (H1c) is also supported ( $\beta=.373, p<.001)$. Hedonic innovativeness has no effect on purchase intention ( $\beta=-.166$, n.s.) so $\mathrm{H} 2 \mathrm{a}$ is not supported, but there is a strong positive effect towards attitude $(\beta=.642, \mathrm{p}<.001)$ 
which supports $\mathrm{H} 2 \mathrm{~b}$. Results partially support $\mathrm{H} 3 \mathrm{a}$ and $\mathrm{H} 3 \mathrm{~b}$ as social innovativeness has a weak negative impact on attitude $(\beta=-.234, p<.05)$ and a weak positive (not the hypothesised negative) influence on purchase intention $(\beta=.155, \mathrm{p}<.05)$. Functional innovativeness does not influence participant comprehension $(\beta=.048$, n.s.) which rejects $\mathrm{H} 4 \mathrm{~b}$, but it positively influences purchase intention $(\beta=.220, \mathrm{p}<.05)$ thus $\mathrm{H} 4 \mathrm{a}$ is supported. Cognitive innovativeness has a moderate positive effect on purchase intention $(\beta=.214, \mathrm{p}<.001)$, therefore H5a is supported and there is a weak negative effect observed between cognitive innovativeness and comprehension $(\beta=-.150, \mathrm{p}<.05)$, which does not supports $\mathrm{H} 5 \mathrm{~b}$ as a positive impact was hypothesised.

Table 3 to be inserted

Based on the findings, we also tested the role of attitude as a mediator. Regression analysis was used to investigate if attitude mediates the effect of hedonic and social innovativeness on purchase intention. Results indicated that hedonic innovativeness was a significant predictor of attitude, $\mathrm{B}=.373, \mathrm{SE}=.054, \mathrm{p}<.001,95 \%$ $\mathrm{CI}=.274, .473$, and that attitude was a significant predictor of purchase intention, $\mathrm{B}=.791, \mathrm{SE}=.545 \mathrm{p}<.001$, $95 \% \mathrm{CI}=.684, .891$. These results support the mediational hypothesis. Hedonic innovativeness indicated a significant predictor of purchase intention after controlling for the mediator, attributional positivity, $\mathrm{B}=.188$, $\mathrm{SE}=.052, \mathrm{p}<.001,95 \% \mathrm{CI}=.087, .290$. Approximately $51 \%$ of the variance in purchase intention was accounted for by the predictors $(\mathrm{R} 2=.51)$. The indirect effect was tested using a percentile bootstrap estimation approach with 5000 samples (Shrout \& Bolger, 2002), implemented with the PROCESS macro Version 3 (Hayes, 2017). These results indicated the indirect coefficient was significant, $\mathrm{B}=.295$, $\mathrm{SE}=.046,95 \% \mathrm{CI}$ $=.176, .330$, and is greater than the direct effect of hedonic innovativeness on purchase intention. Regression analysis was used to investigate the hypothesis that attitude mediates the effect of social innovativeness on purchase intention. Results indicated that social innovativeness was a significant predictor of attitude, $\mathrm{B}=.198$, $\mathrm{SE}=.048, \mathrm{p}<.001,95 \%, \mathrm{CI}=.102, .294$, and that attitude was a significant predictor of purchase intention, $\mathrm{B}$ $=.818, \mathrm{SE}=.051 \mathrm{p}<.001,95 \%, \mathrm{CI}=.717, .918$. These results support the mediational hypothesis. Social innovativeness indicated a significant predictor of purchase intention after controlling for the mediator, attributional positivity, $\mathrm{B}=.1947, \mathrm{SE}=.049, \mathrm{p}<.001$. Approximately $52 \%$ of the variance in purchase intention was accounted for by the predictors $(\mathrm{R} 2=.52)$. The indirect effect was tested using a percentile bootstrap estimation approach with 5000 samples (Shrout \& Bolger, 2002), implemented with the PROCESS macro Version 3 (Hayes, 2017). These results indicated the indirect coefficient was significant, $\mathrm{B}=.1618, \mathrm{SE}=.046$, $95 \% \mathrm{CI}=.0711, .253$ and is greater than the direct effect of social innovativeness on purchase intention.

\section{Discussion and Conclusion}

Consumer innovativeness has been debated in various contexts as an influential factor related to product/service adoption. In most studies, where MCI was not considered, consumer innovativeness had a weak to moderate positive effect on product and service adoption or intention (e.g. Goldsmith et al., 1995; Citrin et al., 2000; Jin and Suh, 2005; Im et al., 2007; Okazaki, 2007). Guoxin et al. (2014) included MCI in their study by looking into its moderating role on relationship between product originality and usefulness, and new product adoption; they found MCI has no direct relation on new product adoption intention. Bartles and Reinders' (2011) review of more than 70 consumer innovativeness papers identified 44 which considered consumer innovativeness as an innate innovativeness trait. Of these 44 papers, only $45 \%$ of them indicated a significant positive relationship between consumer innovativeness and new product adoption, with $35 \%$ finding no significant relationship, and $20 \%$ a partially significant positive relationship. The present study's findings potentially provide an explanation for these contradictory results that lies in differences in the influence of each motivational aspect of consumer innovativeness on innovation adoption. These distinct aspects of consumer innovativeness are not considered in the majority of previous consumer innovativeness studies.

After the introduction of MCI (Vandecasteele and Geunes, 2010), a few studies considered the use of MCI in product adoption. Reinhardt and Gurtner's (2015) study around disruptive and sustaining innovations reported a non-significant difference between disruptive and sustaining innovations with regards to the effect of social, cognitive and functional innovativeness, but a marginally significant difference with regards to the effect 
of hedonic innovativeness on adoption intention. Counter to previous findings, this study found a weak negative relationship between social innovativeness and attitude, demonstrating that socially innovative consumers may respond negatively to RNPs. This finding is in line with relevant literature that explains how innovators are not influenced by others when innovations are consumed privately rather than publicly (Ronald et al., 2006; Kulviwat et al., 2009).

The results from the structural model provide evidence of a direct strong positive relationship between hedonic innovativeness and the attitude of individuals towards RNPs, but did not find a relationship between hedonic innovativeness and purchase intention. This finding is in line with previous studies stating a positive but weak to moderate relationship between innate innovativeness and adoption behaviour (i.e. Reinhardt and Gurtner 2015). However, it appears that this relationship may act through attitude change as is explained through mediation analysis of attitude. Hence it seems the joy of consumption process (peripheral route) positively influence hedonically motivated individual's attitude but not necessarily purchase intention. The current study finds a positive impact of cognitive innovativeness on purchase intention but no impact on comprehension. This finding is in line with existing innovation literature explaining cognitively motivated consumers following central processing route to persuasion (Rogers, 2003; Feiereisen et al., 2008), hence they form a positive intention. However, it appears that due to lack of information and limited existing cognitive structures for the product (Feiereisen et al., 2008) there is no impact on their comprehension.

Similarly, if functional motivation is satisfied, individuals have a positive change in their purchase intention but no change in their level of RNP comprehension. This is in line with previous studies, such as Rauschnabel et al. (2015), which explain how consumers perceiving higher functional benefit of an innovative technology, are more likely to adopt them which can be due to them aiming to solve a consumption problem, leading to an intention to purchase the product. However, this change in intention is not related to the level of comprehension, meaning that either due to limited information available, functionally motivated consumers didn't understand the RNP well enough, or they didn't achieve a separable outcome (i.e. feeling of accomplishment) (Skinner, 1953, Vallerand, 1997). These findings are also in line with ELM, if individuals are hedonically or socially innovated, they follow a peripheral route which can impact their attitude, hence changes in their purchase intention can be explained through their attitude. When individuals are cognitively or functionally motivated, they follow central route which includes the element of comprehension, changes in their purchase intention is not via their comprehension.

Another important insight from the study's findings is related to classical theories of consumer behaviour such as TPB, persuasion theory and decision-making models. The findings indicate that, while interacting with RNPs, comprehension does not necessarily lead to attitude change and intention, but attitude does positively influence both comprehension and purchase intention. Hence, the key to facilitating consumers' adoption of RNPs is to change their attitude towards RNPs, rather than try to help them learn about these products. This challenges some of the literature in favour of the centrality of RNP comprehension in adopting RNPs (GreganPaxton et al., 2002; Feiereisen et al., 2008; Feiereisen, 2009), but it is in line with Salari and Shiu's (2015) findings that innovators influential characteristics when adopting RNPs (but not INPs) are enthusiasm, interest and willingness to adopt a specific product, which are closely linked to attitude. Overall, this study clearly demonstrates that innate innovativeness motivational needs, do not always act harmoniously in relation to the adoption of new products. The study provides key insights into the relationship between the innate innovativeness motivational needs (hedonic, functional, cognitive and social) and an individual's attitude towards, and purchase intentions related to, RNPs. The results indicate the difference in direction (positive or negative) within the relationship between innate innovativeness motivational needs and consumer attitude and purchase intention within the RNP context. This contributes to our understanding of what motivates consumers to adopt RNPs, sheds light on the contradictory findings within the literature concerning the relationship between consumer innovativeness and new product adoption, and adds to the literature surrounding RNP adoption, comprehension, attitude and purchase intention.

These findings are important for marketing practitioners and managers as they can help them to understand the motivation behind RNP adoption. This is important from two aspects, firstly who to target based on the 
business aims, secondly how to promote RNPs towards the target segment. As observed in the findings, if the aim of the business is to increase customers purchase intention, targeting functionally and cognitively motivated innovative individuals is recommended. In order to promote RNPs to satisfy these groups of innovators, product information should be made available to facilitate individual's persuasion through central route. This means more attention to the content of the promotional message including details of the functionality of the product, text and verbal information. Also if the RNP entails a higher utilitarian value, targeting functional innovative individuals is advised.

If the business aim is to change customer's attitude, hedonically motivated innovative individuals should be targeted. This group tends to follow the peripheral route to persuasion, hence paying more attention to the peripheral cues, such as imagery and visuals. For hedonically motivated individuals, the experience of interacting with the RNP interface is rewarding and motivates them intrinsically. Hence in order to attract hedonically innovative individuals, businesses need to enhance aesthetics and enjoyment factors of the RNP promotional materials and platforms. Also, if the RNP is more of a hedonic product, targeting hedonically motivated innovators is advised. By targeting the right customer segment, using correct promotional techniques, practitioners and managers can reduce the risk of RNP failure.

\subsection{Limitation and Future Research}

One of the limitations of this study was the dependent variable of purchase intention. Although researchers have often used purchase intention as a proxy for actual intention, the intention-behaviour gap is highlighted in various fields (e.g. Auger and Devinney, 2007). For the case of RNPs, however, actual behaviour in the marketplace cannot be measured, as these products do not currently exist in the marketplace. This limitation can be addressed in future research by taking a more longitudinal approach to determine the link between innovativeness and actual purchase. Also, RNPs recruited in this study were from the category of home and kitchen gadget, future research needs to consider different categories of RNPs. One suggestion would be to study the motivational elements of crowdfunding contributors such as supporters of Kickstarter projects. Another future research possibility would be to replicate the model used within this study for various other RNPs in different domains, using different forms of product promotion techniques and formats.

Further research should also consider whether the relationship between the different aspects of innovativeness and comprehension, attitude and purchase intention are stable across different types of RNPs. This study only considered one RNP, and while the sample clearly indicated that this product was innovative, what was novel about the product was not assessed. As such, while this study's results clearly showed a differential impact of the innovativeness motivational factors, these factors may not hold with different types of RNPs. Indeed, the key to which type of innovativeness motivational factor has the greatest impact on purchase intention may well lie in the type of RNP considered. Research exploring the connection between RNP characteristics and the different motivational elements of consumer innovativeness, could provide valuable insights into how to approach the promotion of specific RNPs and help reduce new product failures. 


\section{References}

Aboulnasr, K. Tran G.A (2019), "Is love really blind? The effect of emotional brand attachment on the perceived risk of really new products", Journal of Product and Brand Management

Ahn, M. Kang, J. Hustved, G. (2015) A model of sustainable household technology acceptance: Sustainable Household Technology Acceptance Model, International IJC, 40(1)

Ajmal, H. (2019), Promoting upskilling: How a situational growthmindset increases consumers' adoption of really new products, Doctoral dissertations, University of South-Eastern Norway

Alexander, D.L., Lynch, J.G. and Wang, Q. (2008), "As Time Goes By : Do Cold Feet Follow Warm Intentions for Really New Versus Incrementally New Products?", Journal of Marketing Research, Vol.45 No. 3, pp. 307-319.

Anderson, J.C. (1988). "Structural equation modeling in practice: A review and recommended two-step approach.", Psychological Bulletin,Vol. 103,No. 3, pp. 411-423.

Andries, P., Czarnitzki, D. and Hottenrott, H. (2009), Innovation efforts of the Flemish companies: Essential results of the CIS-2007 Survey IN: Debackere, K. and Veugelers, R. (eds.) Flemish indicators book 2009. Science, Innovation, Technology (in Dutch), pp. 117-128.

Babin, B.J., Darden, W.R. and Fgriffin, M. (1994), "Work and or Fun: Measuring Hedonic and Utilitarian Shopping Value.", Journal of Consumer Research,Vol. 20 No. 4, pp. 644-656.

Balat, M. Hanusch, H. (2004), "Recent trends in the research on national innovation systems", Journal of Evolutionary Economics, Vol. 14, pp. 197-210

Bandura, A. (1977), Social Learning Theory. General Learning Press.

Bartels, J. and Reinders, M. (2011), "Consumer innovativeness and its correlates: A propositional inventory for future research", Journal of Business Research, Vol. 64 No. 6, pp. 601-609.

Baumgartner, H. and Steenkamp, J.E.M. (1996), "Exploratory consumer buying behavior: conceptualization and measurement". International Journal of Research Marketing, Vol. 13, pp. 121-137.

Bentler, P.M. and Bonnet, D.C. (1980), "Significance Tests and Goodness of Fit in the Analysis of Covariance Structures." Psychological Bulletin, Vol. 88, No.3. pp. 588-606.

Bickart, B. and Schindler, R.M. (2001) "Internet forums as influential sources of consumer information." Journal of Interactive Marketing, Vol. 15,No. 3, pp. 31-40.

Brem A. and Viardot E. (2015), Adoption of Innovation: Balancing Internal and External Stakeholders in the Marketing of Innovation, Springer International Publishing

Brown, S.A. and Venkatesh, V. (2005), "Model of Adoption of Technology in Households: A Baseline Model Test and Extension Incorporating Household Life Cycle", MIS Quarterly Journal of Electronic Commerce, Vol. 29, No. 3, pp. 399-426.

Cano B., M., Perry, P., Ashman, R. and Waite, K. (2017) "The influence of image interactivity upon user engagement when using mobile touch screens.", Computers in Human Behavior, Vol. 77, pp. 406-412

Chao, C., Reid, M. and Mavondo, F.T. (2012), "Consumer innovativeness influence on really new product adoption. Australasian Marketing Journal, Vol. 20, pp. 211-217.

Cierpicki, S.W. (2000), "Managers' Knowledge of Marketing Principles: The Case of New Product Development.", Journal of Empirical Generalizations in Marketing Science, Vol. 5, pp. 771-790.

Citrin, A.V., Sprott, D.E., Silverman, S.N. and Donald E. Stem, J. (2000), "Adoption of Internet shopping: the role of consumer innovativeness." Industrial Management and Data Systems, Vol. 100, No. 7, pp. 294-300.

Cohen (1988), Statistical power analysis for behavioural sciences. Hillsdale, NJ: Lawrence Erlbaum Associates.

Davis, F.D., Bagozzi, R.P. and Warshaw, P.R. (1989) User acceptance of computer technology: A comparison of two theoretical models. Management Science, 5 (8), 982-1003.

Dedehayir, O. Ort Roland J. Riverola C. and Miralles, F. (2017), "Innovators and early adopters in the diffusion of innovations: A literature review", International Journal of Innovation Management, Vol 2, No. 8; 1-27.

Demirel, Banu; Payne, Ayça Kübra Hızarc1. (2018) "Social Innovation Adoption Behavior: The Case of Zumbara." International Journal of Innovation \& Technology Managemen, Vol. 15,No. 2, pp. 1-19.

Ekdale, B., Singer, JB. Tully, M. (2015), "Making change: Diffusion of technological, relational, and cultural innovation in the newsroom," Journalism \& Mass Communication Quarterly, Vol. 92, No. 4, pp. 938-958. 
Feiereisen, S., Wong, V. and Broderick, A.J. (2008), "Analogies and Mental Simulations in Learning for Really New Products: The Role of Visual Attention." Journal of Product Innovation Management, Vol 25, No. 6, pp. 593-607.

Fornell, C. and Larcker, D.F. (1981) "Evaluating Structural Equation Models with Unobservable Variables and Measurement." Journal of Marketing Research, Vol. 28, pp. 39-50.

Foxall, G.R. (1988), "Consumer Innovativeness: Novelty-Seeking, Creativity and Cognitive Style." Research in Consumer Behavior, Vol. 3, pp. 79-113.

Franks, P.C. and Oliver, G.C. (2012), "Experiential learning and international collaboration opportunities: virtual internships", Library Review, Vol. 61, No. 4, pp. 272 - 285.

Golder, P.N. and Tellis, G.J. (1997), "Will It Ever Fly? Modeling the Growth of New Consumer Durables." Marketing Science, Vol. 16, No. 3, pp. 256-270.

Goldsmith, R.E. and Foxall, G.R. (2003), The Measurement of Innovativeness. IN: Shavinina, L.V. (ed.) The International Handbook on Innovation. Oxford: Elsevier, pp. 321-330.

Goldsmith, R.E., Freiden, J.B. and Eastman, J.K. (1995), "The generality/specificity issue in consumer innovativeness research". Technovation, Vol. 15, No. 10, pp. 601-612.

Goldsmith, R.E. and Hofacker, C.F. (1991), "Measuring consumer innovativeness." Journal of the Academy of Marketing Science, Vol. 19, No. 3, pp. 209-221.

Goldsmith, R.E. and Lafferty, B.A. (2002a), "Consumer respons to Web sites and their influence on advertising effectiveness". Internet Reseaarch: Elletronic Networking Appliations and Policy, Vol. 12, No. 4, pp. 318328.

Gregan-Paxton, J., Hibbard, J.D., Brunel, F.F. and Azar, P. (2002), "So That's What That Is: Examining the Impact of Analogy on Consumers' Knowledge Development for Really New Products." Psychology and Marketing, Vol. 19, No. 6, pp. 533-550.

Guoxin L., Ruijin Z. and Chao W., (2014), "The Role of Product Originality, Usefulness and Motivated Consumer Innovativeness in New Product Adoption Intentions", Journal of Product Innovation Management, Vol. 32, No. 2, pp. 214-223.

Guttentag, D. Smith, S. Potwarka and L. Havitz, M. (2018), "Why Tourists Choose Airbnb: A Motivation-Based Segmentation Study Show less." Journal of Travel research, Vol. 57, No. 3, pp. 342-359

Hair, J.F., Black, W.C., Bebin, B.J. and Anderson, R.E. (2010). Multivariate Data Analysis, 7 ed. New Jersey: Prentice Hall.

Hair, Joseph F Jr, G Tomas M Hult, Christian M Ringle \& Marko Sarstedt (2014) A Primer on Partial Least Squares Structural Equation Modeling (PLS-SEM) Sage Publications: UK.

Hauser, J., Tellis, G.J. and Griffin, A. (2006), "Research on innovation: a review and agenda for marketing science". Marketing Science, Vol. 25, pp. 687-717.

Hayes, A. F. (2017). Introduction to mediation, moderation, and conditional process analysis: A regressionbased approach. Guilford Publications.

Heidenreich, S. and Kraemer, T. (2015) "Innovations- Doomed to Fail? Investigating Strategies to Overcome Passive Innovation Resistance" Product Innovation Management, Vol. 33, No. 3, pp. $277-297$.

Hermida R. (2015) "The problem of allowing correlated errors in structural equation modeling: concerns and considerations", Computational Methods in Social Sciences (CMSS), Vol. 3, No. 1, pp. 5-17

Hirschman, E.C. (1980) "Innovativeness, Novelty Seeking and Consumer Creativity." Journal of Consumer Research, Vol. 7, No. 3, pp. 283-295.

Hirschman, E.C. (1984) "Experience Seeking - a Subjectivist Perspective of Consumption." Journal of Business Research, Vol. 12, No. 1, pp. 115-136.

Hirunyawipada, T. and Paswan, A.K. (2006) "Consumer innovativeness and perceived risk: Implications for high technology product adoption". Journal of Consumer Marketing, Vol. 23, No. 4, pp. 182-198.

Hoeffler, S. (2003), "Measuring Preferences for Really New Products". Journal of Marketing Research, Vol. 40, No. 4, pp. 406-420.

Hoffmann, S. and Soyez, K. (2010), "A cognitive model to predict domain-specific consumer innovativeness." Journal of Business Research, Vol. 63, No.7, pp. 778-785.

Hoyer, W. and Stokbuger-Sauer, N. (2012), "The role of aesthetic taste in consumer." Journal of Academy of Marketing Science, Vol. 40, No. 1, pp.167-180. 
Hu, L.T. and Bentler, P.M. (1999), "Cutoff Criteria for Fit Indexes in Covariance Structure Analysis: Conventional Criteria Versus New Alternatives," Structural Equation Modeling, 6 (1), 1-55.

Hull, C.L. (1943). Principles of behavior. New York, NY: Appleton-Century-Crofts.

Hurt, H.T., Joseph, K. and Cook, C.D. (1977) "Scales for the measurement of innovativeness." Human Communication Research, Vol. 4, No.1, pp. 58-65.

Im, S., Bayus, B. and Mason, C.H. (2003) "An Empirical Study of Innate Consumer Innovativeness, Personal Characteristics and New-Product Adoption Behavior". Journal of the Academy of Marketing Science, Vol. 31, No. 1, pp. 61-73.

Im, S., Mason, C. and Houston, M. (2007), "Does innate consumer innovativeness relate to new product/service adoption behavior? The intervening role of social learning via vicarious innovativeness". Journal of the Academy of Marketing Science, Vol. 35, No. 1, pp. 63-75.

Irani, T. (2000) "Prior Experience, Perceived Usefulness and the Web: Factors Influencing Agricultural Audiences' Adoption of Internet Communication Tools." Journal of Applied Communications, Vol. 84, No. 2, pp. 49-63.

Jansson, J. (2011) Consumer eco-innovation adoption: assessing attitudinal factors and perceived product characteristics, Business Strategy and the Environment, Wiley Online Library

Jin B. Suh Y.G. (2005) "Integrating effect of consumer perception factors in predicting private brand purchase in a Korean discount store context." Journal of Consumer Marketing, Vol. 22, No. 2, pp. 62-71

Jöreskog, K. and Long, J.S. (1993). Introduction IN: Kenneth, A.B. and Scott, J. (eds.) Testing Structural Equation Models. Newbury Park, CA: Sage.

Jürgensen K., Guesalaga R. (2017) "Young consumers' innovativeness in apparel choices: A model including consumer self confidence", International Journal of Consumer Studies, Vol. 42, No. 2, pp. 255-263

Kim J., Forsythe S. (2007) "Hedonic usage of product virtualization technologies in online apparel shopping," International Journal of Retail and Distribution Management, Vol. 35, No. 6, pp. 502-514

Kim J.S. (2016) "An Investigation of Key Factors Affecting the Adoption of Smartphone in Three Regions", International Journal of Innovation and Technology Management, Vol. 13, No.6

Kline, R.B. (2005) Principles and practice of structural equation modeling, 2 ed. New York: Guilford Press.

Lee, S. (2010), "Two Essays on Product Design and Consumer Evaluation," PhD, University of Central Florida.

Lei, P.W. and Wu, Q. (2007) "Introduction to Structural Equation Modeling: Issues and Practical Considerations." Educational Measurement: Issues and Practice, Vol. 26, No. 3, pp. 33-43.

Li, G., Zhang, R. and Wang, C. (2015) "The role of product originality, usefulness and motivated consumer innovativeness in new product adoption intentions', Journal of Product Innovation Management, Vol. 32, No. 2, pp. 214-223.

Lyu, J., Hahn, K. and Sadacha, A. (2018), "Understanding millennial consumer's adoption of 3D printed fashion products by exploring personal values and innovativeness." Fashion and Textile, Vol. 5, No. 11

K Lyytinen, Y Yoo, RJ Boland Jr - Information Systems Journal, 2016 Digital product innovation within four classes of innovation networks, Wiley Online Library

Mahadzirah Mohamad \& Asyraf Afthanorhan* \& Zainudin Awang \& Morliyati Mohammad, 2019. "Comparison Between CB-SEM and PLS-SEM: Testing and Confirming the Maqasid Syariah Quality of Life Measurement Model," The Journal of Social Sciences Research, Academic Research Publishing Group, vol. 5(3), pages 608-614, 03-2019.

Manning, K.C., Bearden, W.O. and Madden, T.J. (1995." Consumer Innovativeness and the Adoption Process." Journal of Consumer Psycology, Vol. 4, No. 4, pp. 329-345.

Mcintosh, C. (2006) "Rethinking fit assessment in structural equation modelling: A commentary and elaboration on Barrett". Personality and Individual Differences, Vol. 42, No. 5, pp. 859-867.

Midgley, D. (1977) Innovation and New Product Marketing. New York: Halsted Press, John Wiley and sons, Inc.

Midgley, D. and Dowling, G. (1978), "Innovativeness: the concept and its measurement." Journal of Consumer Research, Vol. 4, pp. 229-242.

Midgley, D. and Dowling, G. (1993), "A Longitudinal-Study of Product Form Innovation - the Interaction between Predispositions and Social Messages". Journal of Consumer Research, Vol. 19, No. 4, pp. 611-625.

Moon, J., Chadee, D. and Tikoo, S. (2008) "Culture, product type, and price influences on consumer purchase intention to buy personalized products online." Journal of Business Research, Vol. 61, No. 1, pp. 31-39. 
Nishitani, K. and Itoh M. (2016) "Product innovation in response to environmental standards and competitive advantage: a hedonic analysis of refrigerators in the Japanese retail market," Journal of Cleaner Production, Vol. 113, pp. 873-883

Ogertschnig, M. and Van Der Heijden, H. (2004) A short-form measure of attitude towards using a mobile information service. IN: Tan, Y.H. and Vogel, D. (eds.) Proceedings of the 17th Bled Electronic Commerce conference. Bled.

Okazaki, S. (2007) "Lessons learned from i-mode: What makes consumers click wireless banner ads?" Computers in Human Behavior, Vol. 23, pp. 1692-1719.

Pagani, M. (2007), "A Vicarious Innovativeness Scale for 3G Mobile Services: Integrating the Domain Specific Innovativeness Scale with Psychological and Rational Indicators." Technology Analysis and Strategic Management, Vol. 19, No. 6, pp. 709-728.

Paivio, A. (1986) Mental Representations: A Dual Coding Approach. New York: Oxford University Press.

Paivio, Allan , (1991), Images in Mind: The Evolution of a Theory. New York: Harvester Wheatsheaf

Paivio, A. (2006) Dual Coding Theory and Education. Paper presented at Pathways to Literacy Achievement for High Poverty Children, The University of Michigan School of Education, September 29-October. Available from: http://www.csuchico.edu/ nschwartz/paivio.pdf. (accessed June 7, 2015)

Paivio, Allan , (2007), Mind and Its Evolution: A Dual Coding Theoretical Approach. Mahwah, NJ: Lawrence Erlbaum Associates

Pan, J. N., and Nguyen, H.T.N. (2015), "Achieving customersatisfaction through product-service systems." European Journal of Operational Research, Vol. 247, No. 1, pp. 179-190

Pearson, P.H. (1970) "Relationships Between Global and Specific Measures of Novelty Seeking." Journal of Consulting and Clinical Psychology, Vol. 34, No. 2, pp. 199-204.

Petty, R.E. and Cacioppo, J.T. (1981). Attitudes and Persuasion: Classic and Contempormy Approaches. Dubuque: IA: Wm. C. Brown.

Petty, R.E. and Cacioppo, J.T. (1986) Communication and Persuasion: Central and Peripheral Routes to Attitude Change. New York: Springer-Verlag.

Phillips, B.J. (2000) "The Impact of Verbal Anchoring on Consumer Response to Image Ads." Journal of Advertising, Vol. 29, No. 1, pp. 15-24.

Prince, J. and Simon, D. (2009) "Has the Internet accelerated the diffusion of new products?" Research Policy, Vol. 38, No. 8, pp. 1266-1277.

Raju, P.S. (1980) "Optimum Stimulation Level - Its Relationship to Personality, Demographics, and Exploratory-Behavior." Journal of Consumer Research, Vol. 7, No. 3, pp. 272-282.

Ratneshwar, S. and Chaiken, S. (1991) "Comprehension's Role in Persuasion: The Case of Its Moderating Effect on the Persuasive Impact of Source Cues." Journal of Consumer Research, Vol. 18, No. 1, pp. 52-62.

Rauschnabel P.A., Brem, A. Ivens, B.S. (2015) "Who will buy smart glasses? Empirical results of two premarket-entry studies on the role of personality in individual awareness and intended adoption of Google Glass wearables", Computers in Human Behaviour, Vol. 49 , pp. 635-647

Reinhardt R. Gurtner S. (2015) "Differences between early adopters of disruptive and sustaining innovations", Journal of Business Research, Vol. 68, No. 1, pp. 137-145.

Rezvani, Z. Jansson, J. Bengtsson, M. (2018). "Consumer motivations for sustainable consumption: The interaction of gain, normative and hedonic motivations on electric vehicle adoption", Business Strategy and the Environment, Vol. 27, No. 8, pp. 1272-1283.

Roehrich, Gilles (2004) "Consumer Innovativeness: Concepts and Measurements", Journal of Business Research, Vol. 57, No. 6, pp. 671-77.

Rogers, E. (1983). Diffusion of Innovations, 3 ed. New York: Free Press.

Rogers, E. (1995). Diffusion of Innovations, 4 ed. New York: The Free Press.

Rogers, E. (2003). Diffusion of innovations, 5 ed. New York: NY: Free Press.

Ryan, R.M. and Deici, E.L. (2000). "Intrinsic and extrinsic motivations: Classic definitions and new directions." Contemporary Educational Psychology, Vol. 25, pp. 54-67.

Salari, N. and Shiu E., (2015). "Establishing a culturally transferrable consumer innovativeness scale for radical and really new innovations in new markets." Journal of Marketing Analytics, Vol. 3, No. 2, pp. 47-68.

Scott, S. G., \& Bruce, R. A. (1995). Decision-making style: The development and assessment of a new measure. Educational and Psychological Measurement, 55(5), 818-831. 
Simonson, I. and Nowlis, S.M. (2000). "The Role of Explanations and Need for Uniqueness in Consumer Decision Making: Unconventional Choices Based on Reasons." Journal of Consumer Research, Vol. 27, No. 1, pp. 49-68.

Sharma, S., Mukherjee, S., Kumar, A., and Dillon, W.R. (2005), "A simulation study to investigate the use of cutoff values for assessing model fit in covariance structure models," Journal of Business Research, 58 (1), 935-43.

Shrout, P. E., \& Bolger, N. (2002). Mediation in experimental and nonexperimental studies: New procedures and recommendations. Psychological Methods, 7(4), 422-445

Skinner, B.F. (1953). Science and Human Behavior. New York: Macmillan.

Sohag, K., Ara Begum, R. Syed Abdullah, S.M. and Jaafar M. (2015). "Dynamics of Energy Use, Technological Innovation, Economic Growth and Trade Openness in Malaysia." Energy, Vol. 90, No. 2, pp. 1497-150

Song, M., C. Droge, S. Hanvanich, and R. Calantone. 2005. "Marketing and Technology Resource Complementarity: An Analysis of their Interaction Effect in two Environmental Contexts." Strategic Management Journal 26 (3): 259-276. doi: 10.1002/smj.450

Steenkamp, J.E.M., Ter Hofstede, F. and Wedel, M. (1999). "A crossnational investigation into the individual and national cultural antecedents of consumer innovativeness." Journal of Marketing Intelligence and Planning, Vol. 63, pp. 55-69

Tellis, G.J., Yin, E. and Bell, S. (2009). "Global consumer innovativeness: Cross-country differences and demographic commonalities." Journal of International Marketing, Vol. 17, No. 2, pp. 1-22.

Thoenig, M. and Verdier, T. A (2003). "Theory of defensive skill-biased innovation and globalization" , American Economic Review, Vol. 93, pp. 709-728

Tian, K.T., Bearden, W.O. and Hunter, G.L. (2001). "Consumers' Need for Uniqueness: Scale Development and Validation." Journal of Consumer Research, Vol. 28 , No.1, pp. 50-66.

Tian, K.T. and Mckenzie, K. (2001). "The Long-Term Predictive Validity of the Consumers' Need for Uniqueness Scale". Journal of Consumer Psychology, Vol. 10, No. 3, pp. 171-193.

Vallerand, R.J. (1997). Toward a Hierarchical Model of Intrinsic and Extrinsic Motivation IN: Zanna, M.P. (ed.) Advances in Experimental Social Psychology, 29 ed. New York: Academic Press; 271-360.

Vandecasteele, B. and Geunes, M. (2010) "Motivated consumer innovativeness: concept, measurement, and validation". International Journal of Research in Marketing, Vol. 27, No. 4, pp. 308-318.

Vandecasteele, B (2010) Innovative Consumers: Who, Why and How to Target? Unpublished Thesis, Ghent University.

Venkatesh, A. and Nicosia, F. (1997) "New Technologies For the Home-Development of a Theoretical Model of Household Adoption and Use." Advances in Consumer Research, Vol. 24, pp. 522-528.

Venkatraman, M.P. and Price, L.L. (1990) "Differentiating between cognitive and sensory innovativeness: Concepts, measurement, and implications." Journal of Business Research Policy, Vol. 20, No. 4, pp. 293 315 .

Voss, K.E., Spangenberg, E.R. and Grohmann, B. (2003), "Measuring the Hedonic and Utilitarian Dimensions of Consumer Attitude." Journal of Mark2eting Research, Vol. 40, No. 3, pp. 310-320.

Visnjic I.,Wiengarten, F. Neely A. (2016) Only the Brave: Product Innovation, Service Business Model Innovation, and Their Impact on Performance", Journal of Product Innovation Management, Vol. 33, No. 1, pp. $36-52$

Wang, Qing, Dacko, Scott G. and Gad, Marwa (2008), Factors influencing consumers' evaluation and adoption intention of really-new products or services : prior knowledge, innovativeness and timing of product evaluation. In: 35th Annual Conference of the Association-for-Consumer-Research, Memphis, TN, Oct 2528, 2007. Published in: Advances in Consumer Research, Vol. 35, pp. 416-422.

Weijters, B. and Roehrich, G. (2004). Consumer Innovativeness and Personal Values of Openness and Selfenhancement. Unpublished manuscript.

Wheaton, B., Muthén, D.F., Alwin, B.B. and Summers, G.F. (1977), Assessing reliability and stability in panel models. IN: Heise, D.R. (ed.) Sociological methodology. San Francisco:: Jossey-Bass; 84-136.

Wilke, J. and Sorvillo, N. (2005). Targeting Early Adopters - A Means for New Product Survival. ACNielsen BASES publication. 
Yang, K., (2010) "The effects of technology self-efficacy and innovativeness on consumer mobile data service adoption between American and Korean consumers". Journal of International Consumer Marketing, Vol 22, No. 2, pp. 117-127.

Zang, J. and Li, Y. (2017) Technology capabilities, marketing capabilities and innovation ambidexterity, Technology Analysis \& Strategic Management, 29 (1): 23-27. DOI: 10.1080/09537325.2016.1194972

Zhao, M., Hoeffler, S. and Dahl, D.W. (2009) "The Role of Imagination-Focused Visualization on New Product Evaluation." Journal of Marketing Research, Vol. 46, No. 1, pp. 46-55.

Ziamou PL (2003) "Commercializing new technologies: consumers' response to a new interface", Journal of Product Innovation Management, Vol. 19, No. 5, pp. 365-374

$\mathrm{Xu}, \mathrm{K}$. and Lombard, M. (2017). "Persuasive Computing: Feeling Peer Pressure from Multiple Computer Agents", Computers in Human Behavior, Vol. 74, pp. 152-162

Zenobia B.A. and Weber C.M (2011) "An investigation of key factors affecting the adoption of smartphone in three regions" International Journal of Innovation and Technology Management, Vol. 8, No. 4, pp. 535-555

Zhang, D., Zhou, L., Briggs, R.O. and Nunamaker, J.F.Jr. (2006)" Instructional video in e-learning: Assessing the impact of interactive video on learning effectiveness". Information and Management, Vol. 43, No. 1, pp. $15-27$. 


\section{Appendices}

\section{Appendix 1}

Perceived Product Newness scale and results:

Please answer the questions with Yes/No.

- Have you seen this product before?

- Do you have any information about this product (According to Gregan-Paxton et al., 2002)

Participants are asked to score each of the below statements on a five point Likert scale ranging from "strongly disagree" to "strongly agree":

- I feel quite certain of the benefits I could expect to get if I adopted this product. (Reverse coded)

- I'm quite sure of what the relevant trade-offs are among the costs and benefits of buying and using this product. (Reverse coded)

- I'll have to change my behavior significantly to attain the potential benefits of this new product.

- Using this product would allow me to do things that I can't easily do now.

(Alexander et al., 2008)

\section{Appendix 2}

\section{Bio Robot Fridge}

The Bio Robot utilizes a special biopolymer gel that has the ability to suspend the food in its place, cool and well preserved once inserted. Rather than having shelves or drawers, the non-sticky, odourless gel does all the work - it envelopes itself around food items, creating a "separate capsule" for each product. Surface tension holds each food item in its place, but at the same time lets you access the products stored through a self-parting, non-sticking, you can say, 'smart surface' that folds away as needed.

The next function that the gel performs is to keep the food items cool. Nanotechnology is at the very heart of the design as the gel consists of a colony of bio-mechanical robots. These microscopic beings can identify and assess the necessary temperature required for each stored item and then automatically adjust the cooling process to the optimum temperature best suited to a product. It's like your food now gets individual attention and care.

This cooling comes from a process called luminescence - whereby, heat energy is absorbed from the environment and converted into visible light through a cooling process. Therefore, cooling all that contained within.

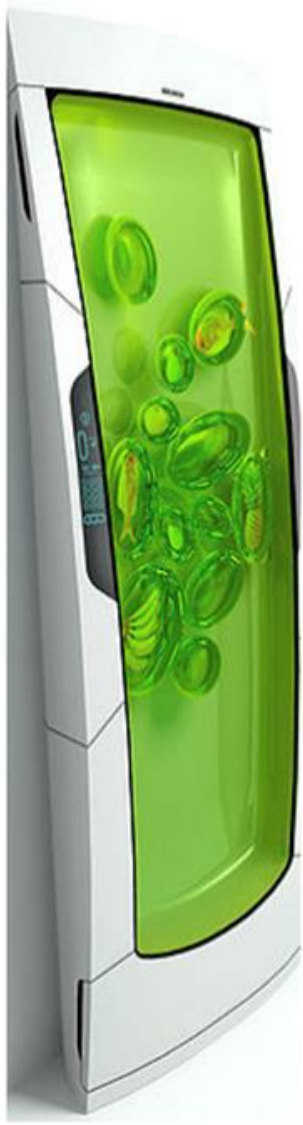

